\title{
TANTANGAN PROFESI KEGURUAN PADA ERA REVOLUSI INDUSTRI 4.0
}

\author{
Fatkhul Mubin \\ fatkhulmubin90@gmail.com
}

\section{A. PENDAHULUAN}

Profesi keguruan merupakan profesi yang terus berkembang. Pemikiran tentang profesi keguruan kerap kali diperbincangkan. Bagi seorang guru, pengetahuan tentang profesi keguruan harus benar-benar dimiliki untuk dapat meningkatkan profesionalitas dalam melaksanakan tugas. Perkembangan profesi keguruan harus melihat perkembangan era yang terus berkembang di tengah kehidupan manusia. Era demi era telah dilalui oleh manusia secara sadar mapun tidak. Karena perkembangan era dalam kehidupan manusia terlihat dan dapat dirasakan oleh sebagian manusia yang terbuka diri untuk selalu mempelajari atau update mengenai perkembangan teknologi informasi yang dapat mempermudah kerja manusia itu sendiri.

Perubahan era, dari era revolusi (mesin uap) 1.0, era elektrisity (listrik) 2.0, era komputerisasi (3.0), 4.0 (digitalisasi) dan 5.0 (society) memberikan dampak bagi perkembangan semua profesi yang ada dalam kehidupan, termasuk salah satunya dalam profesi keguruan yang mengalami perkembangan sesuai era yang terus berkembang. Era 4.0 adalah era yang sangat memberikan dampak bagi profesi keguruan karena di era ini digitalisasi tidak dapat ditutupi perkembangannya untuk memberikan manfaat yang lebih besar bagi guru yakni dapat lebih mempermudah kegiatan KBM dengan siswa, maupun untuk membuat perangkat kerja maupun tugasnya. Segala hal menjadi tanpa batas dan tidak terbatas akibat perkembangan internet dan digital di era 4.0.

Oleh karena itu, makalah ini mengangkat judul pembahasan yang sesuai dengan era yang sudah ada dalam kehidupan walaupun kini telah memasuki era 5.0 mengenai pengembangan profesi keguruan di era 4.0 yang mana era ini memberi dampak bagi kegiatan tugas atau proses dalam menjalani profesi keguruan. Pendidikan di era revolusi industri 4.0 menuntut adanya penataan manajemen pendidikan yang baik dan professional. Guru yang profesional menekankan pada kemampuan guru dalam mentransfer ilmu pengetahuan, kemampuan guru dalam merancang strategi, dan kemampuan guru dalam mengimplemetasikan pembelajarannya.

Bertitik pada latar belakang, maka penulis mencatat beberapa rumusan masalah untuk dijadikan sebagai bahan pembahasan. Rumusan masalah dalam makalah ini adalah :

1. Apa maksud dari era 4.0?

2. Bagaimana pengembangan guru profesional di era 4.0?

3. Bagaimana peranan profesi keguruan dalam menghadapi tantangan di era 4.0 ? 
Adapun tujuan pembuatan makalah ini adalah :

1. Untuk mengetahui maksud dari era 4.0

2. Untuk mengetahui pengembangan guru profesional di era 4.0

3. Untuk memahami peranan profesi keguruan dalam menghadapi tantangan di era 4.0

\section{B. PEMBAHASAN}

Pengertian Era 4.0

Industri 4.0 adalah nama otomasi dan pertukaran data terkini dalam teknologi pabrik. Istilah ini mencakup sistem siber-fisik, internet untuk segala, komputasi awan, dan komputasi kognitif. ${ }^{1}$ Istilah 4.0 awal mula istilah era ini adalah terjadinya revolusi industri di seluruh dunia, yang mana merupakan sebuah revolusi industri keempat. Dikatakan sebagai sebuah revolusi, karena perubahan yang terjadi memberikan efek besar kepada ekosistem dunia dan tata cara kehidupan. Revolusi industri 4.0 bahkan diyakini dapat meningkatkan perekonomian dan kualitas kehidupan secara signifikan. Revolusi Industri 4.0 Mulai dicetuskan pertama kali oleh sekelompok perwakilan ahli berbagai bidang asal Jerman, pada tahun 2011 lalu di acara Hannover Trade Fair. Dipaparkan bahwa industri saat ini telah memasuki inovasi baru, dimana proses produksi mulai berubah pesat. Pemerintah Jerman menganggap serius gagasan ini dan tidak lama menjadikan gagasan ini sebuah gagasan resmi. Setelah resminya gagasan ini, pemerintah Jerman bahkan membentuk kelompok khusus untuk membahas mengenai penerapan Industri 4.0 .

\footnotetext{
1"Industri 4.0" https://id.wikipedia.org/wiki/Industri_4.0, (diakses pada 10 November 2019), Saihu, S. (2019). RINTISAN PERADABAN PROFETIK UMAT MANUSIA MELALUI PERISTIWA TURUNNYA ADAM AS KE-DUNIA. Mumtaz: Jurnal Studi Al-Quran dan Keislaman, 3(2), 268279,

Saihu, S. (2019). Pendidikan Pluralisme Agama: Kajian tentang Integrasi Budaya dan Agama dalam Menyelesaikan Konflik Sosial Kontemporer. Jurnal Indo-Islamika, 9(1), 67-90, Saihu, S. (2019). IMPLEMENTASI MANAJEMEN BALANCED SCORECARD DI PONDOK PESANTREN JAM'IYYAH ISLAMIYYAH TANGERANG SELATAN. Mumtaz: Jurnal Studi Al-Quran dan Keislaman, 3(1), 1-22, Saihu, S. (2019). KOMUNIKASI PENDIDIK TERHADAP ANAK BERKEBUTUHAN KHUSUS DI SEKOLAH KHUSUS ASY-SYIFA LARANGAN. Andragogi: Jurnal Pendidikan Islam dan Manajemen Pendidikan Islam, 1(3), 418-440, Saihu, S., \& Marsiti, M. (2019). PENDIDIKAN KARAKTER DALAM UPAYA MENANGKAL RADIKALISME DI SMA NEGERI 3 KOTA DEPOK, JAWA BARAT. Andragogi: Jurnal Pendidikan Islam dan Manajemen Pendidikan Islam, 1(1), 23-54, Saihu, S. (2019). KONSEP MANUSIA DAN IMPLEMENTASINYA DALAM PERUMUSAN TUJUAN PENDIDIKAN ISLAM MENURUT MURTADHA MUTHAHHARI. Andragogi: Jurnal Pendidikan Islam dan Manajemen Pendidikan Islam, 1(2), 197-217.

Saihu, S., \& Rohman, B. (2019). PEMBENTUKAN KARAKTER MELALUI MODEL PENDIDIKAN TRANSFROMATIFE LEARNING PADA SANTRI DI PONDOK PESANTREN NURUL IKHLAS BALI. Edukasi Islami: Jurnal Pendidikan Islam, 8(02), 435-452.
} 
Pada 2015, Angella Markel mengenalkan gagasan Revolusi Industri 4.0 di acara World Economic Forum (WEF). Jerman sendiri menggelintirkan modal sebesar $€ 200$ juta untuk menyokong akademisi, pemerintah, dan pebisnis untuk melakukan penelitian lintas akademis mengenai Revolusi Industri 4.0. Tidak hanya Jerman yang melakukan penelitian serius mengenai Revolusi Industri 4.0, namun Amerika Serikat juga menggerakkan Smart Manufacturing Leadership Coalition (SMLC), sebuah organisasi nirlaba yang terdiri dari produsen, pemasok, perusahaan teknologi, lembaga pemerintah, universitas dan laboratorium yang memiliki tujuan untuk memajukan cara berpikir di balik Revolusi Industri 4.0.

Revolusi Industri 4.0 menerapkan konsep automatisasi yang dilakukan oleh mesin tanpa memerlukan tenaga manusia dalam pengaplikasiannya. Dimana hal tersebut merupakan hal vital yang dibutuhkan oleh para pelaku industri demi efisiensi waktu, tenaga kerja, dan biaya. Penerapan Revolusi Industri 4.0 di pabrik-pabrik saat ini juga dikenal dengan istilah Smart Factory. Tidak hanya itu, saat ini pengambilan ataupun pertukaran data juga dapat dilakukan on time saat dibutuhkan, melalui jaringan internet. Sehingga proses produksi dan pembukuan yang berjalan di pabrik dapat termotorisasi oleh pihak yang berkepentingan kapan saja dan dimana saja selama terhubung dengan internet.

Bila kita melihat kembali Revolusi Industri 3.0 dimana merupakan titik awal dari era digital revolution, yang memadukan inovasi di bidang Elektronik dan Teknologi Informasi. Perkembangan Revolusi Industri 3.0 ke Revolusi Industri 4.0 sangat signifikan, hal baru yang sebelumnya tidak pernah ada di era Revolusi Industri 3.0 mulai ditemukan. Para ahli meyakini era ini merupkan era dari Revolusi Industri 4.0, dikarenakan terdapat banyak inovasi baru di Industri 4.0, diantaranya Internet of Things (IoT), Big Data, percetakan 3D, Artifical Intelligence (AI), kendaraan tanpa pengemudi, rekayasa genetika, robot dan mesin pintar. Salah satu hal terbesar didalam Revolusi Industri 4.0 adalah Internet of Things.

IoT (Internet of Things) memiliki kemampuan dalam menyambungkan dan memudahkan proses komunikasi antara mesin, perangkat, sensor, dan manusia melalui jaringan internet. Contoh kecil, sebelumnya di era Revolusi Industri 3.0 kita hanya dapat mentransfer uang melalui ATM atau teller bank, saat ini kita dapat melakukan transfer uang dimana saja dan kapan saja selama kita terhubung dengan jaringan internet. Cukup dengan aplikasi yang ada di dalam gadget kita dan koneksi internet, kita dapat mengontrol aktifitas keuangan kita dimanapun dan kapanpun.

Selain Internet of Things, ada juga istilah Big Data yang berperan penting dalam Revolusi Industri 4.0. Big data adalah seluruh informasi yang tersimpan di cloud computing. Analitik data besar dan komputasi awan, akan membantu deteksi dini cacat dan kegagalan produksi, sehingga memungkinkan pencegahan atau peningkatan produktivitas dan kualitas 
suatu produk berdasarkan data yang terekam. ${ }^{2}$ Perkembangan era 1.0 hingga 4.0 dapat digambarkan seperti di bawah ini:

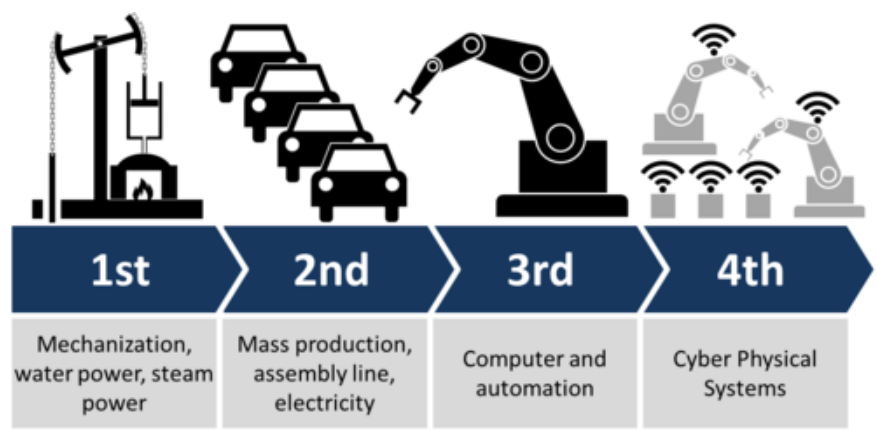

Di era 4.0 atau era digitalisasi ini, arus informasi kian deras dan tidak dapat dibendung karena semua orang bebas membuat dan menggunakan informasi, sama halnya yang dikatakan oleh Lon Safko bahwa, "di era digital semua orang bisa menjadi produser terhadap informasi yang dia miliki. ${ }^{3}$

\section{Pengembangan Guru Profesional Di Era 4.0}

Pendidikan adalah investasi sumber daya manusia (SDM) jangka panjang yang mempunyai nilai strategis bagi kelangsungan peradaban manusia di dunia. Salah satu komponen penting dalam pendidikan adalah guru. Guru dalam konteks pendidikan mempunyai peranan yang besar dan strategis. Hal ini disebabkan karena guru yang berada di barisan terdepan dalam pelaksanaan pendidikan. Guru yang langsung berhadapan dengan

2"Mengenal Lebh Jauk Revolusi Indusri 4.0". https://binus.ac.id/knowledge/2019/05/mengenal-lebih-jauh-revolusi-industri-4-0/. (diakses pada 10 November 2019).

${ }^{3}$ Ilham Prisgunanto, Pemaknaan Arti Informasi di Era Digital, PTIK (Jakarta: 2018), Saihu, S., \& Taufik, T. (2019). PERLINDUNGAN HUKUM BAGI GURU. Al Amin: Jurnal Kajian Ilmu dan Budaya Islam, 2(2), 105-116. Saihu, S. (2020). KONSEP PEMBAHARUAN PENDIDIKAN ISLAM MENURUT FAZLURRAHMAN. Andragogi: Jurnal Pendidikan Islam dan Manajemen Pendidikan Islam, 2(1), 82-95, Saihu, S. (2020). ETIKA MENUNTUT ILMU MENURUT KITAB TA'LIM MUTA'ALIM. Al Amin: Jurnal Kajian Ilmu dan Budaya Islam, 3(1), 99-112, Saihu, Aziz, A., Mubin, F., \& Sarnoto, A. Z. (2020). Design of islamic education based on local wisdom (An analysis of social learning theories in forming character through ngejot tradition in bali). International Journal of Advanced Science and Technology, 29(6), 1278-1293, Ronaldo, R., Zulfikar, A., Saihu, Ismail, \& Wekke, I. S. (2020). International relations of the asia pacific in the age of trump. Journal of Environmental Treatment Techniques, 8(1), 244-246, Saihu, M. M., \& Aziz, A. (2020). Implementasi Metode Pendidikan Pluralisme Dalam Mata Pelajaran Pendidikan Agama Islam. Belajea; Jurnal Pendidikan Islam, 5(1), 131-150, Saihu, M. (2019). Urgensi 'Urf dalam Tradisi Male dan Relevansinya dalam Dakwah Islam di Jembrana-Bali. Jurnal Bimas Islam, 12(1), 173-201, Saihu, S. (2020). The Effect of Using Talking Stick Learning Model on Student Learning Outcomes in Islamic Primary School of Jamiatul Khair, Ciledug Tangerang. Tarbawi: Jurnal Keilmuan Manajemen Pendidikan, 6(01), 61-68.Saihu, S. (2020). Pendidikan sosial yang terkandung dalam Surat At-Taubah Ayat 71-72. Edukasi Islami: Jurnal Pendidikan Islam, 9(01), 127-148. 
peserta didik untuk mentransfer ilmu pengetahuan dan teknologi, sekaligus mendidik dengan nilai-nilai positif melalui bimbingan dan keteladanan. Guru adalah praktisi pendidikan yang sesungguhnya.

Dengan terbukanya saluran informasi, maka tidak adanya pembatasan terhadap akses informasi menyebabkan perubahan drastis dalam konstelansi kehidupan manusia. Begitupula dengan profesi keguruan yang didalam kegiatannya memiliki pengembangan dalam melakukan interaksi dengan peserta didiknya.

Guru yang profesional merupakan faktor penentu proses pendidikan yang berkualitas. Guru dalam era teknologi informasi dan komunikasi sekarang ini bukan hanya sekadar mengajar (transfer of knowledge) melainkan harus menjadi manajer belajar. Hal tersebut mengandung arti, setiap guru diharapkan mampu menciptakan kondisi belajar yang menantang kreativitas dan aktivitas siswa, memotivasi siswa, menggunakan multimedia, multimetode dan multisumber agar mencapai tujuan pembelajaran yang diharapkan.

Menanggapi persoalan tersebut, dalam peningkatan kualitas pengajaran, guru harus bisa mengembangkan tiga intelegensi dasar siswa. Yaitu, intelektual, emosional dan moral, tiga unsur itu harus ditanamkan pada diri murid sekuat-kuatnya agar terpatri di dalam dirinya. Hal lain yang harus diperhatikan guru adalah dimensi spiritual siswa. Intelektual siswa harus luas, agar ia bisa menghadapi era global dan tidak ketinggalan zaman apalagi sampai terbawa arus. Selain itu, dimensi emosional dan spiritual pelajar harus terdidik dengan baik, agar bisa melahirkan perilaku yang baik dan siswa bisa bertahan di antara tarik-ulur pengaruh demoralisasi di era global dengan prinsip spiritualnya.

Di samping itu, untuk mempertahankan profesinya, guru juga harus memiliki kualifikasi pendidikan profesi yang memadai, memiliki kompetensi keilmuan sesuai dengan bidang yang ditekuninya, mampu berkomunikasi baik dengan peserta didiknya, mempunyai jiwa kreatif dan produktif, mempunyai etos kerja dan komitmen tinggi terhadap profesinya. Dengan demikian, tantangan guru di era global tidak akan menggusurnya pada posisi yang tidak baik.

Peran guru dan tugas guru sebagai salah satu faktor determinan bagi keberhasilan pendidikan, terutama dalam menghadapi pendidikan di era revolusi industri 4.0. Keberadaan dan peningkatan profesional guru menjadi wacana yang sangat penting. Pendidikan di era revolusi industri 4.0 menuntut adanya penataan manajemen pendidikan yang baik dan professional. Guru yang profesional menekankan pada kemampuan guru dalam mentransfer ilmu pengetahuan, kemampuan guru dalam merancang strategi, dan kemampuan guru dalam mengimplemetasikan pembelajarannya. ${ }^{4}$

4 Suyati, Meningkatkan Peranan Guru Profesional Dalam Menghadapi Era Revolusi Indistri 4.0. (Palembang: 2019), Aziz, A., \& Saihu, S. (2019). Interpretasi Humanistik Kebahasaan: Upaya Kontekstualisasi Kaidah Bahasa Arab. Arabiyatuna: Jurnal Bahasa Arab, 3(2), 299-214, Saihu, S. (2019). PENDIDIKAN KARAKTER BERBASIS KEARIFAN LOKAL (STUDI DI JEMBRANA BALI). Edukasi Islami: Jurnal Pendidikan 
Menurut Jufri (2013) bahwa guru profesional merupakan profesional dengan tugas utama mendidik, mengajar, membimbin, mengarahkan, melatih, menilai mengevaluasi peserta didik. Sikap dan profesional guru di dalam pendidikan mempunyai peran untuk mempersiapkan peserta didik menjadi generasi yang mampu menguasai keahlian yang mantap.

Menurut Kunandar, ada beberapa tantangan globalisasi yang harus disikapi guru dengan mengedepankan profesionalismenya, yaitu:

1. Perkembangan ilmu pengetahuan dan teknologi yang begitu cepat dan mendasar. Dengan kondisi ini guru harus bisa menyesuaikan diri secara responsif, arif dan bijaksana. Responsif artinya guru harus bisa menguasai dengan baik produk IPTEK, terutama yang berkaitan dengan dunia pendidikan. Tanpa penguasaan IPTEK yang baik, maka guru menjadi tertinggal dan menjadi korban IPTEK serta menjadi guru yang "isoku iki" (aku cuma bisa ini).

2. Krisis moral yang melanda Indonesia. Akibat pengaruh IPTEK dan globalisasi telah terjadi pergeseran nilai-nilai yang ada dalam kehidupan masyarakat. Melalui pendidikan, guru memiliki tantangan tersendiri untuk menanamkan nilai-nilai moral pada generasi muda.

3. Krisis sosial, seperti kriminalitas, kekerasan, pengangguran dan kemiskinan yang terjadi dalam masyarakat. Akibat perkembangan industri dan kapitalisme, maka muncul masalah-masalah sosial dalam masyarakat. Mereka yang lemah secara pendidikan, akses dan ekonomi akan menjadi korban.

Ini merupakan tantangan guru untuk merespons realitas ini melalui dunia pendidikan. Sebab, sekolah merupakan lembaga pendidikan formal yang sudah mendapat kepercayaan dari masyarakat, sehingga harus mampu menghasilkan peserta didik yang siap hidup dalam kondisi dan situasi bagaimanapun.

Berbagai kegiatan di dalam masyarakat hanya menerima para profesional, artinya barang siapa yang tidak profesional tidaka akan survive. Karena mereka tidak mampu berkompetisi dengan orang lain yang lebih profesional atau juga profesi ainnya yang lebih kompetitif. Jika profesi gur

Islam, 8(01), 69-90. Şahin, C. RELIGIA, Saihu, S., \& Mailana, A. (2019). Teori pendidikan behavioristik pembentukan karakter masyarakat muslim dalam tradisi Ngejot di Bali. Ta'dibuna: Jurnal Pendidikan Islam, 8(2), 163-176, Mubin, F. KEADILAN DALAM GENDER: KAJIAN KEPEMIMPINAN WANITA DALAM ISLAM1, Saihu, M. (2019). Merawat Pluralisme Merawat Indonesia (Potret Pendidikan Pluralisme Agama Di Jembrana-Bali). Deepublish, Mubin, F. (2019). TAFSIR EMANSIPATORIS: PEMBUMIAN METODOLOGI TAFSIR PEMBEBASAN. Mumtaz: Jurnal Studi Al-Quran dan Keislaman,3(1), 131-151, Mubin, F. MODEL-MODEL PEMBELAJARAN BERBASIS MADRASAH DAN KEGIATAN LAIN YANG DIPERLUKAN DI DALAMNYA (FAKTOR PENDUKUNGNYA). 
tidak kompetitif dan tidak profesional, maka degna sendirinya akan berakibat kepada mati atau hilangnya profesi tersebut dari masyarakat. Hal ini tentunya sangat bertentangan dengan masyarakat abad 21 (merupakan satu kesatuan dari masyarakat teknologi, masyarakat terbuka, dan masyarakat madani) yang menuntut adanya perkembangan manusia, dan itu tidak mungkin tanpa adanya guru yang profesional. Guru-guru yang profesional inilah yang diharapkan dapat membawa atau mengantar peserta didiknya mengarungi dunia ilmu pengetahuan dan teknologi untuk memasuki masyarakat abad 21 yang melek ilmu pengetahuan dan teknolog, dan sangat kompetitif. Jika guru tidak mengusai ilmu pengetahuan dan teknologi tidak mungkin mereka dapat membantu dan membimbing peserta didiknya mengarungi dunia pengetahuan dan teknologi tersebut.

Penguasaan ilmu pengetahuan dan teknologi oleh guru yang profesional bukanlah pengetahuan yang setengah-tengah tetapi merupakan penguasaan ilmu pengetahuan dan teknologi yang tuntas, karena ilmu pengetahuan dan teknologi itu sendiri berkembang dengan cepat. Guru yang tidak mempunyai ilmu pengetahuan yang kuat, tuntas dan setengah-setengah akan tercecer dan tidak mampu mengikuti perkembangan ilmu pengetahuan dan teknologi. Ia akan berada jauh di belakang, dan akhirnya akan tertinggal dari profesinya.

Jadi jelaslah bahwa profesi guru adlaah suatu profesi yang harus terusmenerus berkembang karena praktis pendidikan akan terus menerus terjadi dan unik bagi setiap individu dan masyarkaat di dalam situasi dan waktu yang berbeda sesuai dengan perkembanga ilmu pengetahuan dan teknologi. Sinyalemen ini memberikan makna bahwa guru sebagai pelaku proses pendidikan harus terus menerus mengubah diri, sehingga mereka memiliki ilmu pengeratahuan yang kuat, tuntas dan tidak setengah-setengah sebagai profesional kependidikan.

Selain itu, karena profesi guru merupakan suaut profesi untuk membantu dan membimbing perkembangan anak didik (manusia), mak ahubungan natara manusia dengan manusia menjadi penting untk diperhatikan dalam rangka pengembangan profesionalisme guru. Dengan kata lain, pengembangan diri guru sebagai profesional kependidikan harus dapat membantu guru bukan hanya sekedar memiliki ilmu pengetahuan yang kuat, tuntas dan tidak setengah-setengah tetapi tidak kalah pentingnya untuk membantu mereka memiliki kepribadian yang matang dan terus berkembang. Dengan penguasaan ilmu pengetahuan dan teknologi yang kuat, tuntas dan tidak setengah-setengah, serta didukung dengan kepemilikan kepribadian yang prima, maka diharapkan guru akan terampil membangkitkan minat peserta didik kepada ilmu pengetahuan dan teknologi. Dan akhirnya melalui proses pendidikan yang profesional yang dilaksanakan oleh pelaku-pelaku (khususnya guru yang profesional dengan karakteristiknya tersebut di atas), maka peserta didik dapat dibantu dean dibimbing untuk mampu berkompetitif di masyarakat abad 21 yang ditandai dengan perubahan ilmu pengetahuan dan teknologi secara cepat.

Proses pengembangan profesionalisme guru ini dapat ditumbuhkembangkan bukanhanya untuk berlangsung di LPTK tetapi juga harus 
terjadi di dalam praktek-praktek pendidikan lainnya (pre-service and inservice). Bersama-sama dengan usaha-usaha lain (misalnyakerjasmaa dengan organisasi profesi), lembaga-lembaga pre-service danin-service harus menjaid satu kesatuan yang tidak terpisahka, membangun kerja sama dan saling mendukung untuk melahirkan guru-guru yang profesional dalam rangka menyajikan proses pendidikan yang profesional bagi anak didik agar dapat berperan aktif dalam kehidupan masyarakat abad 21.5

Setidaknya terdapat tiga karakteristik yang harus dimiliki masyarakat di abad 21, karena pada abad inilah era insustri 4.0 semakin berkembang. Tiga karakteristik yang harus dimiliki adalah sebagai berikut:

1. Masyarakat Teknologi

Masyarakat teknologi yang dimaksud adalah suatu masyarakat yang telah melek teknologi dan menggunakan berbagai aplikasi teknologi, sehingga dapat mengubah cara berpikir, bertindak bahkan mengubah bentuk dan pola hidup manusia yang sama sekali berlainan dengan kehidupan sebelumnya. Dalam masyarakat seperti itu, peran pendidikan dan guru sangat penting dan strategis, terutama dalam memberikan bimbingan, dorongan, Semangat, fasilitas kepada masyarakat dan peserta didik untuk memperoleh ilmu pengetahuan dan keterampilan menggunakan teknologi. Selain itu, tidak kalah pentingnya adalah peran pendidikan dalam memberikan arahan dan bimbingan agar penguasaan teknologi tidak menjadi bumerang bagi masyarakat, yang disebabkan kurangnya penghayatan terhadap etika.

2. Masyarakat Terbuka

Lahirnya teknologi komunikasi yang demikian maju, membuat dunia menjadi satu seolah tanpa sekat, sehingga komunikasi antar pribadi menjadi makin dekat dan hampir tanpa hambatan, yang pada akhirnya melahirkan masyarakat terbuka. Dalam masyarakat terbuka, antara bangsa satu dengan bangsa lain dapat saling mempengaruhi dalam berbagai hal, termasuk mempengaruhi budaya bangsa lain. Hal itu mengancam kehidupan masyarakat lain oleh karena adanya kemungkinan penguasaan atau dominasi oleh mereka yang lebih kuat, yang berprestasi dan yang memiliki modal terhadap masyarakat yang lemah, tidak berdaya dan miskin. Untuk itu, dalam masyarakat terbuka diperlukan manusia yang mampu mengembangkan kapasitasnya agar menjadi manusia dan bangsa yang kuat, ulet, kreatif, disiplin, dan berprestasi, sehingga tidak menjadi korban dan tertindas oleh zaman yang penuh dengan persaingan.

3. Masyarakat Madani

Masyarakat madani merupakan wujud dari suatu masyarakat terbuka, di mana setiap individu mempunyai kesempatan yang sama untuk memperoleh ilmu pengetahuan dan keterampilan menggunakan teknologi, berkarya, berprestasi dan memberikan sesuatu sesuai dengan kapasitasnya. Masyarakat madani tumbuh dan berkembang bukan dengan sendirinya dan

5 “Pengembangan Profesi Guru "http://www.sarjanaku.com/2010/11/pengembanganprofesi-keguruan.html. (diakses pada November 2019) 
bukan tanpa upaya terencana, tetapi masyarakat yang dibangun melalui pendidikan. Kunci terwujudnya masyarakat madani adalah pendidikan, karena melalui pendidikan dapat dibangun sumberdaya yang berkualitas dengan kepribadian yang sesuai dengan budaya serta kesadaran individu hidup berdampingan untuk mencapai tujuan bersama. ${ }^{6}$

Revolusi industri 4.0 dimana teknologi telah menjadi basis dalam kehidupan manusia. Segala hal menjadi tanpa batas dan tidak terbatas akibat perkembangan internet dan teknologi digital. Oleh karena itu, ada 4 tahap perkembangan profesional guru yaitu: era pra-profesional, era profesional otonom, era profesional kolegial dan era profesional, dimana di era 4.0 menuntut peran guru yang semakin tinggi dan optimal. Empat tahap perkembangan profesionalisme guru adalah sebagai berikut:

1. Era Pra-Profesional

Di era ini, mengajar dianggap sebagai pekerjaan yang hanya membutuhkan keterampilan teknis yang sederhana namun sarat dengan tuntutan administrative. Oleh karena itu, seorang dapat menjadi guru mengajar. Pembimbingan masih sebatas pemberian semangat dan juga memanfaatkan kemampuan sendiri.

2. Era Profesional Otonom

Era ini berawal pada abad 60 an ketika profesi guru sudah lebih baik dibandingkan dengan era sebelumnya. Guru dipandang sebagai pekerjaan profesional. Profesional Otonom meningkatkan status guru dan juga gaji guru.

3. Era Profesional Kolegial

Era ini mulai saat terjadi ledakan pengetahuan di tahun 80an, meluasnya tuntutan kurikulum, meningkatknya jumlah siswa berkebutuhan khusus di kelas biasa dan perubahan lingkungan yang cepat.

4. Era Profesional (era 4.0)

Dimulai abad 21, di saat sekolah dituntut lebih memperhatikan pasar atau konsumen yang kompetitif. Pekerjaan guru menjadi lebih kompleks yaitu tidak hanya berkaitan dengan pengajaran, namun juga pengembangan hubungan dengan orang tua dan komunitas sekolah.

Guru di era 4.0 memiliki karakteristik yag spesifik dibanding guru di abad sebelumnya, antara lain: Memiliki semangat juang dan etos kerja yang tinggi, mampu memanfaatkan iptek sesuai tuntutan lingkungan sosial dan budaya sekitar, berperilaku profesional tinggi dalam mengemban tugas dan menjalani profesi, memiliki wawasan ke depan yang luas dan tidak satu pandangangan dalam melihat permasalahan, mengemban prinsip kerja bersaing dan bersanding. ${ }^{7}$

Peranan Profesi Keguruan Dalam Menghadapi Tantangan Di Era 4.0

Mengingat strategisnya peran guru dalam pendidikan, apalagi di era

${ }^{6}$ Fitri Oviyanti, Tatangan Pengembangan Pendidiakan Keguruan di Era Global, Vol. 7, No. 2. Nadwa Jurnal Pendidikan Islam. (Palembang: 2013).

${ }^{7}$ Mutiara Aprillinda, Perkembangan Guru Profesional di era revolusi indutri 4.0, (Palembang: 2019) 
global ini, maka kebutuhan akan guru yang berkualitas menjadi sebuah keniscayaan demi masa depan bangsa yang gemilang. Kebutuhan akan guru yang berkualitas yang semakin tinggi saat ini harus disikapi secara positif oleh para pengelola pendidikan guru. Respons positif ini harus ditunjukkan dengan senantiasa meningkatkan mutu program pendidikan yang ditawarkannya. Perbaikan mutu pendidikan pada jenjang pendidikan tinggi ini jelas akan membawa dampak positif bagi penciptaan guru yang berkualitas kelak di kemudian hari.

Dalam UU Nomor 14 Tahun 2005 tentang Guru dan Dosen, dinyatakan bahwa Guru adalah pendidikan profesional dengan tugas utama mendidik, mengajar, membimbing, mengarahkan, melatih, menilai, dan mengevaluasi peserta didik pada jalur pendidikan formal.

Profesi menjadi seorang guru menjadi profesi yang tidak akan pernah tergantikan oleh perkembangan teknologi yang sangat luar biasa. Meskipun setiap orang saat ini dapat menimba ilmu dari berbagai sumber melalui kecanggihan teknologi yang serba digital. Namun, seorang guru tetap dibutuhkan karena profesi yang mulia ini bukan hanya berfungsi untuk mentransfer ilmu pengetahuan saja melainkan juga menanamkan nilai-nilai kehidupan serta keteladanan yang tidak bisa dipelajari dari saluran informasi apapun.

Berikut ini beberapa tantangan yang harus disikapi dan dipahami oleh guru di lembaga pendidikan terutama dalam menghadapi era revolusi industri 4.0, antara lain sebagai berikut:

a. Perkembangan dan kemajuan ilmu pengetahuan, teknologi dan informasi yang begitu pesat.

b. Moral, adab, dan tingkah laku yang telah mengalami kepunahan.

c. Kritisnya kemasyarakatan diantaranya kriminalitas, kekerasan, pengangguran, dan banyaknya warga miskin. Krisis personalitas sebagai warga negara Indonesia yang berdaulat.

d. Perdagangan bebas yang meraja lela, baik di tingkat ASEAN, Asia Pasifik dan mendunia.

Keadaan tersebut, tentunya sangat memerlukan dan membutuhkan guru yang memiliki yang idealis, berkompeten dan berpendidikan yang tinggi, dalam rangka membekali peserta didiknya dengan berbagai kemampuan yang dibutuhkan untuk melawan arus atau era yang sedang dan terus berubah. Maka tidak heran jika seorang guru merupakan faktor terpenting dalam menerapkan dan mengembangkan pendidikan dan tentunya tidak terlepas dari beberapa upaya yang harus dilakukannya, antara lain:

a. Guru mampu menguasai materi pelajaran, ilmu pengetahun, informasi dan teknologi yang akan digunakan dan diajarkannya kepada peserta didik.

b. Guru mencerminkan tingkah laku dan sikap yang dapat diteladani peserta didknya.

c. Guru mempunyai kecintaan dan komitmen terhadap profesinya sebagai pendidik.

d. Guru menguasai berbagai macam metode dan strategi yang akan digunakannya dalam pembelajaran dan teknik penilaian. 
e. Guru bersikap terbuka dalam menghadapi pembaharuan dan wawasan dalam pengembangan kompetensi dirinya, terutama dalam hal pembaharuan.

Memasuki era revolusi indutri 4.0, tugas guru tidaklah semakin ringan, setidaknya guru haruslah mampu mempersipkan dan meningkatkan kemampuan yang dimiliki dengan baik dalam menghadapi era tersebut, setidaknya ada 4 upaya yang harus dilaksanakannya, sebagaimana yang dikemukakan oleh Wardiman Djojonegoro, yaitu:

a. Memiliki kemampuan dalam menguasai keahlian dalam suatu bidang yang berkaitan dengan ilmu pengetahuan dan teknologi.

b. Mampu bekerja secara profesioanl dengan otoritas mutu dan keunggulan.

c. Menghasilkan karya-karya unggul yang mamu bersaing secara global sebagai hasil dari keahlian dan profesionalnya dan di era 4.0

d. Mempunyai karakteristik masyarakat teknologi, masyarakat madani yang secara keseluruhan berpegaruh pada visi, misi dan tujuan pendidikan. Pertumbuhan teknologi akan berpengaruh pada cara dan bentuk hidup manusia.

Dengan demikian, hendaknya guru meningkatkan kualifikasi keilmuan dan akademis yang dimilikinya, mengubah kearifan dan kebijaksanaan yang masih bertumpu pada pola-pola klasik, memperbaiki sikap dan tingkah laku yang selama ini dilakukannya dihadapan peserta didik, dan melek akan perkembangan dan kemajuan teknologi yang berkembang dengan pesat.

Guru haruslah mampu mengambil sisi positif dan mengantisipasi sisi negatif dari perkembangan informasi dan teknolgi di era industri 4.0 yang sangat berdampak pada proses pembelajarannya. Apabila hal tersebut tidak disikapi dan dicermati dengan baik maka akan sia-sia. Kehadiran smartphone saat ini salah satunya telah menjadikan peserta didik mudah dan cepat dalam mendapatkan informasi terbaru yang up to date dan hal ini sangat berpengaruh dalam KBM yang dilakukan oleh guru jika tidak ditindak lanjuti dengan cepat.

Aplikasi tersebut, memang diciptakan untuk memberikan kemudakan bagi peserta didik berbuat dan bekerja serta memberikan kebahagiaan dan kesenangan bagi penggunanya. Artinya, kemajuan dan perkembangan tersebut, hendaknya disikapi dan ditindak lanjuti, serta dijadikan sebagai sumber pendukung dalammeningkatkan dan mengembangkan pendidikan agar lebih baik dan relevan serta sesuai dengan kebutuhan peserta didik di era revolusi industry $4.0 .^{8}$

\section{KESIMPULAN}

${ }^{8}$ Aldo Redho Syam, Guru dan Pengembangan Kurikulum Pendidikan Agama Islam di era revolusi indutri 4.0, Vol.13. Tadris, (Ponorogo: 2018). p. 11-13 
Dari pembahasan dengan sumber yang ada maka penulis menarik sebuah kesimpulan mengenai Pengembangan Profesi Keguruan di Era 4.0 sebagai berikut:

1. Revolusi Industri 4.0 menerapkan konsep automatisasi yang dilakukan oleh mesin tanpa memerlukan tenaga manusia dalam pengaplikasiannya. Salah satu hal terbesar didalam Revolusi Industri 4.0 adalah Internet of Things. IoT (Internet of Things) memiliki kemampuan dalam menyambungkan dan memudahkan proses komunikasi antara mesin, perangkat, sensor, dan manusia melalui jaringan internet.

2. Guru yang profesional merupakan faktor penentu proses pendidikan yang berkualitas. Guru dalam era teknologi informasi dan komunikasi sekarang ini bukan hanya sekadar mengajar (transfer of knowledge) melainkan harus menjadi manajer belajar. Hal tersebut mengandung arti, setiap guru diharapkan mampu menciptakan kondisi belajar yang menantang kreativitas dan aktivitas siswa, memotivasi siswa, menggunakan multimedia, multimetode dan multisumber agar mencapai tujuan pembelajaran yang diharapkan. Segala hal menjadi tanpa batas dan tidak terbatas akibat perkembangan internet dan teknologi digital. Oleh karena itu, ada 4 tahap perkembangan profesional guru yaitu: era pra-profesional, era profesional otonom, era profesional kolegial dan era profesional

3. Memasuki era revolusi indutri 4.0, tugas guru tidaklah semakin ringan, setidaknya guru haruslah mampu mempersipkan dan meningkatkan kemampuan yang dimiliki dengan baik dalam menghadapi era tersebut, dengan demikian, hendaknya guru meningkatkan kualifikasi keilmuan dan akademis yang dimilikinya, mengubah kearifan dan kebijaksanaan yang masih bertumpu pada pola-pola klasik, memperbaiki sikap dan tingkah laku yang selama ini dilakukannya dihadapan peserta didik, dan melek akan perkembangan dan kemajuan teknologi yang berkembang dengan pesat. 


\section{DAFTAR PUSTAKA}

“Industri 4.0" https://id.wikipedia.org/wiki/Industri_4.0, (diakses pada 10 November 2019).

"Mengenal Lebh Jauk Revolusi Indusri 4.0". https://binus.ac.id/knowledge/2019/05/mengenal-lebih-jauh-revolusi-industri-4-0/. (diakses pada 10 November 2019).

"Pengembangan Profesi Guru "http://www.sarjanaku.com/2010/11/pengembanganprofesi-keguruan.html. (diakses pada November 2019)3

Aprillinda, Mutiara, Perkembangan Guru Profesional di era revolusi indutri 4.0, (Palembang: 2019)

Aziz, A., \& Saihu, S. (2019). Interpretasi Humanistik Kebahasaan: Upaya Kontekstualisasi Kaidah Bahasa Arab. Arabiyatuna: Jurnal Bahasa Arab, 3(2), 299-214

Mubin, F. (2019). TAFSIR EMANSIPATORIS: PEMBUMIAN METODOLOGI TAFSIR PEMBEBASAN. Mumtaz: Jurnal Studi Al-Quran dan Keislaman, 3(1), 131-151.

Mubin, F. KEADILAN DALAM GENDER: KAJIAN KEPEMIMPINAN WANITA DALAM ISLAM1,

Mubin, F. MODEL-MODEL PEMBELAJARAN BERBASIS MADRASAH DAN KEGIATAN LAIN YANG DIPERLUKAN DI DALAMNYA (FAKTOR PENDUKUNGNYA).

Oviyanti, Fitri, Tatangan Pengembangan Pendidiakan Keguruan di Era Global, Vol. 7, No. 2. Nadwa Jurnal Pendidikan Islam. Palembang: 2013.

Prisgunanto, Ilham Prisgunanto, Pemaknaan Arti Informasi di Era Digital, PTIK (Jakarta: 2018).

Ronaldo, R., Zulfikar, A., Saihu, Ismail, \& Wekke, I. S. (2020). International relations of the asia pacific in the age of trump. Journal of Environmental Treatment Techniques, 8(1), 244-246.

Şahin, C. RELIGIA.

Saihu, Aziz, A., Mubin, F., \& Sarnoto, A. Z. (2020). Design of islamic education based on local wisdom (An analysis of social learning theories in forming character through ngejot tradition in bali). International Journal of Advanced Science and Technology, 29(6), 1278-1293.

Saihu, M. (2019). Urgensi 'Urf dalam Tradisi Male dan Relevansinya dalam Dakwah Islam di Jembrana-Bali. Jurnal Bimas Islam, 12(1), 173-201.

Saihu, M. (2019). Merawat Pluralisme Merawat Indonesia (Potret Pendidikan Pluralisme Agama Di Jembrana-Bali). Deepublish.

Saihu, M. M., \& Aziz, A. (2020). Implementasi Metode Pendidikan Pluralisme Dalam Mata Pelajaran Pendidikan Agama Islam. Belajea; Jurnal Pendidikan Islam, 5(1), 131-150. 
Saihu, S. (2019). IMPLEMENTASI MANAJEMEN BALANCED SCORECARD DI PONDOK PESANTREN JAM'IYYAH ISLAMIYYAH TANGERANG SELATAN. Mumtaz: Jurnal Studi Al-Quran dan Keislaman, 3(1), 1-22.

Saihu, S. (2019). KOMUNIKASI PENDIDIK TERHADAP ANAK BERKEBUTUHAN KHUSUS DI SEKOLAH KHUSUS ASY-SYIFA LARANGAN. Andragogi: Jurnal Pendidikan Islam dan Manajemen Pendidikan Islam, 1(3), 418-440.

Saihu, S. (2019). KONSEP MANUSIA DAN IMPLEMENTASINYA DALAM PERUMUSAN TUJUAN PENDIDIKAN ISLAM MENURUT MURTADHA MUTHAHHARI. Andragogi: Jurnal Pendidikan Islam dan Manajemen Pendidikan Islam, 1(2), 197-217.

Saihu, S. (2019). PENDIDIKAN KARAKTER BERBASIS KEARIFAN LOKAL (STUDI DI JEMBRANA BALI). Edukasi Islami: Jurnal Pendidikan Islam, 8(01), 69-90.

Saihu, S. (2019). Pendidikan Pluralisme Agama: Kajian tentang Integrasi Budaya dan Agama dalam Menyelesaikan Konflik Sosial Kontemporer. Jurnal IndoIslamika, 9(1), 67-90,

Saihu, S. (2019). RINTISAN PERADABAN PROFETIK UMAT MANUSIA MELALUI PERISTIWA TURUNNYA ADAM AS KE-DUNIA. Mumtaz: Jurnal Studi Al-Quran dan Keislaman, 3(2), 268-279,

Saihu, S. (2020). ETIKA MENUNTUT ILMU MENURUT KITAB TA'LIM MUTA'ALIM. Al Amin: Jurnal Kajian Ilmu dan Budaya Islam, 3(1), 99-112.

Saihu, S. (2020). KONSEP PEMBAHARUAN PENDIDIKAN ISLAM MENURUT FAZLURRAHMAN. Andragogi: Jurnal Pendidikan Islam dan Manajemen Pendidikan Islam, 2(1), 82-95.

Saihu, S. (2020). Pendidikan sosial yang terkandung dalam Surat At-Taubah Ayat 71-72. Edukasi Islami: Jurnal Pendidikan Islam, 9(01), 127-148.

Saihu, S. (2020). The Effect of Using Talking Stick Learning Model on Student Learning Outcomes in Islamic Primary School of Jamiatul Khair, Ciledug Tangerang. Tarbawi: Jurnal Keilmuan Manajemen Pendidikan, 6(01), 6168.

Saihu, S., \& Mailana, A. (2019). Teori pendidikan behavioristik pembentukan karakter masyarakat muslim dalam tradisi Ngejot di Bali. Ta'dibuna: Jurnal Pendidikan Islam, 8(2), 163-176.

Saihu, S., \& Marsiti, M. (2019). PENDIDIKAN KARAKTER DALAM UPAYA MENANGKAL RADIKALISME DI SMA NEGERI 3 KOTA DEPOK, JAWA BARAT. Andragogi: Jurnal Pendidikan Islam dan Manajemen Pendidikan Islam, 1(1), 23-54.

Saihu, S., \& Rohman, B. (2019). PEMBENTUKAN KARAKTER MELALUI MODEL PENDIDIKAN TRANSFROMATIFE LEARNING PADA SANTRI DI PONDOK PESANTREN NURUL IKHLAS BALI. Edukasi Islami: Jurnal Pendidikan Islam, 8(02), 435-452.

Saihu, S., \& Taufik, T. (2019). PERLINDUNGAN HUKUM BAGI GURU. $A l$ Amin: Jurnal Kajian Ilmu dan Budaya Islam, 2(2), 105-116.

Suyati, Meningkatkan Peranan Guru Profesional Dalam Menghadapi Era Revolusi Indistri 4.0. (Palembang: 2019). 
Syam, Aldo Redho Guru dan Pengembangan Kurikulum Pendidikan Agama Islam di era revolusi indutri 4.0, Vol.13. Tadris, Ponorogo: 2018 